\title{
Clinical Significance of Hepatic Capsular Enhancement in Multi-Directional Computed Tomography with Fitz-Hugh-Curtis Syndrome
}

\author{
Jeong-Ju Yoo ${ }^{1, *}$, Jung Seok Park ${ }^{1, *}$, Bora Lee², Min Hee Lee ${ }^{3}$, Sang Gyune Kim', Young Seok Kim \\ 'Department of Gastroenterology and Hepatology, Soonchunhyang University Bucheon Hospital, Soonchunhyang University School of Medicine, Bucheon; \\ ${ }^{2}$ Department of Biostatistics, Chung-Ang University Graduate School, Seoul; ${ }^{3}$ Department of Radiology, Soonchunhyang University Bucheon Hospital, \\ Soonchunhyang University School of Medicine, Bucheon, Korea
}

\begin{abstract}
Objective: Fitz-Hugh-Curtis syndrome (FHCS) is characterized by perihepatitis in patients with pelvic inflammatory disease. Hepatic capsular enhancement in arterial phase of abdominal computed tomography (CT) is usually required for definite diagnosis. The objective of this study was to assess clinical significance of intensity of hepatic capsular enhancement in CT of patients with FHCS. Methods: A total of 86 patients who had hepatic capsular enhancement in CT due to FHCS were retrospectively enrolled. The hepatic capsular enhancement was divided into three patterns according to the intensity of enhancement by an expert radiologist: $A$, partial weak enhancement; B, partial strong or diffuse weak enhancement; and C, diffuse strong enhancement. Other clinical and laboratory parameters such as duration of admission were also evaluated.

Results: Hepatic capsular enhancement in CT was classified into pattern $A(n=28)$, pattern $B(n=35)$, and pattern $C(n=23)$. Hospital stay was significantly shorter in pattern $A(6.1 \pm 2.4$ days, $P<0.001)$ than that in pattern $B(7.2 \pm 2.9$ days $)$ or pattern $C(7.7 \pm 2.2$ days $)$. Subjective perihepatic pain duration was well correlated with the degree of hepatic capsular enhancement $(P<0.001)$. In multivariate analysis, the intensity of capsular enhancement was significantly associated with hospital stay after adjusting other factors. However, laboratory inflammation marker was not directly correlated with hepatic capsular enhancement.

Conclusion: Enhancement pattern of CT scan in patients with FHCS is closely related to its clinical severity and the course of this disease.
\end{abstract}

Keywords: Fitz-Hugh-Curtis syndrome; Enhancement; Computed tomography

\section{INTRODUCTION}

Fitz-Hugh-Curtis syndrome (FHCS) is a perihepatitis due to intraperitoneal extension of pelvic inflammatory disease (PID) [1,2]. If sexually active women presenting with right upper quadrant (RUQ) abdominal pain visit a hospital, FHCS could be considered [2-5]. Although the accurate incidence of FHCS is currently unknown, the incidence of PID has been estimated to be $4 \%$ to $14 \%$ while that of PID in adolescent females can be as high as $27 \%$ $[1,6,7]$. Classical standard diagnosis of FHCS needs invasive procedures such as laparoscopy or laparotomy with detection of fibrous adhesion or identification of Neisseria gonorrhoeae or Chlamydia trachomatis in a specimen acquired from a capsular lesion of the liver [8-11]. However, for most cases, this syndrome can be well controlled by antibiotics [1-4,12]. Therefore, it is mostly diagnosed by non-invasive methods in recent years [13]. The diagnosis of FHCS is made by combining typical clinical symptom such as RUQ pain and typical imaging findings [14]. Although sonography can show widening of the right anterior renal space and loculation of fluid in the hepatorenal space, computed tomography (CT) is the most commonly used imaging tool for diagnosis of FHCS nowadays [15,16]. If arterial-phase CT reveals characteristic contrast enhancement of liver capsule, a confirmative diagnosis of FHCS can be made. Capsular enhancement seen on early arterialphase images reflects increased blood flow or inflammation at the inflamed hepatic capsule [17]. In contrast, violin string-like adhe-
Correspondence to: Sang Gyune Kim

Department of Gastroenterology and Hepatology, Digestive Research Center and Liver Clinic, Soonchunhyang University Bucheon

Hospital, 170 Jomaru-ro, Wonmi-gu, Bucheon 14584, Korea

Tel: +82-32-621-5215, Fax: +82-32-621-6079, E-mail: mcnulty@schmc.ac.kr

*These two authors contributed equally to this work as co-first authors.

Received: Sep. 27, 2019 / Accepted after revision: Nov. 28, 2019
(C) 2019 Soonchunhyang Medical Research Institute This is an Open Access article distributed under the terms of the Creative Commons Attribution Non-Commercial License (http://creativecommons.org/licenses/by-nc/4.0/). 
Yoo JJ, et al. • Capsular Enhancement Pattern in Fitz-Hugh-Curtis Syndrome

sions are characteristics of the chronic phase of this disease while enhancement on delayed phase CT scan reflects early capsular fibrosis [18].

Although the use of arterial phase of CT has increased the diagnostic yield of FHCS and the value of dynamic CT in diagnosis of FHCS has been well researched, there are few reports regarding the relationship between clinical manifestation and capsular enhancement pattern. Therefore, the objective of the present study was to identify the clinical significance of capsular enhancement pattern of multidetector CT (MDCT) in patients with FHCS.

\section{MATERIALS AND METHODS}

\section{Study populations}

The present study protocol was reviewed and approved by the Institutional Review Board of Soonchunhyang University Bucheon Hospital (IRB approval no., 2016-07-007-001). This study retrospectively enrolled 86 females diagnosed with FHCS who had undergone MDCT between January 2005 and July 2017 at Soonchunhyang University Bucheon Hospital. Initially, a total of 121 female patients who visited the outpatient clinic or emergency room with suspected FHCS were retrieved. Among them, 35 patients were excluded for the following reasons: (1) monophasic contrast enhanced CT was performed ( $\mathrm{n}=10)$, (2) no evidence of PID or gynecological symptoms $(n=7)$, and (3) medical records of patients were insufficient $(n=18)$. Finally, a total of 86 patients who were diagnosed as HFCS with MDCT examination were included in this study.

The diagnostic criteria of FHCS were as follows: the presence of RUQ pain, clinically diagnosed PID, hybrid capture test for Chla- mydia trachomatis, and leukocytosis or tests for elevation of C-reactive protein (CRP) response to antibiotics.

\section{Imaging study}

The hepatic capsular enhancement of dynamic CT findings was classified into three patterns: (1) pattern A, partial weak enhancement (Fig. 1A); (2) pattern B, partial strong or diffuse weak enhancement (Fig. 1B); and (3) pattern C, diffuse strong enhancement (Fig. 1C). The extent of enhancement was defined as partial (less than half of entire capsule) or diffuse (the above) while the intensity of enhancement was defined as weak (less intense than enhancement of portal vein) or strong (the above). It was reported by an independent radiologist who was blinded to clinical information. All CT images were analyzed by a single radiologist with more than 10 years of experience.

CT was performed with a 64-row MDCT scanner (LightSpeed VCT; GE Medical Systems, Milwaukee, WI, USA) or a 16-detector row CT scanner (Sensation 16; Siemens Medical Solutions, Erlangen, Germany), covering the top down to the floor of the liver. Patients were given intravenously $150 \mathrm{~mL}$ iomeprol (350 mg of iodine [/mL], Iomeron 350; Bracco, Milan, Italy) at a rate of $3 \mathrm{~mL} / \mathrm{sec}$ using a high-pressure syringe. CT scanning began automatically when the threshold of abdominal aorta of the diaphragmatic dome level reached 100 Hounsfield unit, which was monitored by a software of contrast tracing. The scanning included three phases: arterial phase (15-25 seconds), portal phase (90 seconds), and delayed phase (180-210 seconds).

\section{Statistics}

Frequencies and percentages were used for descriptive statistics.
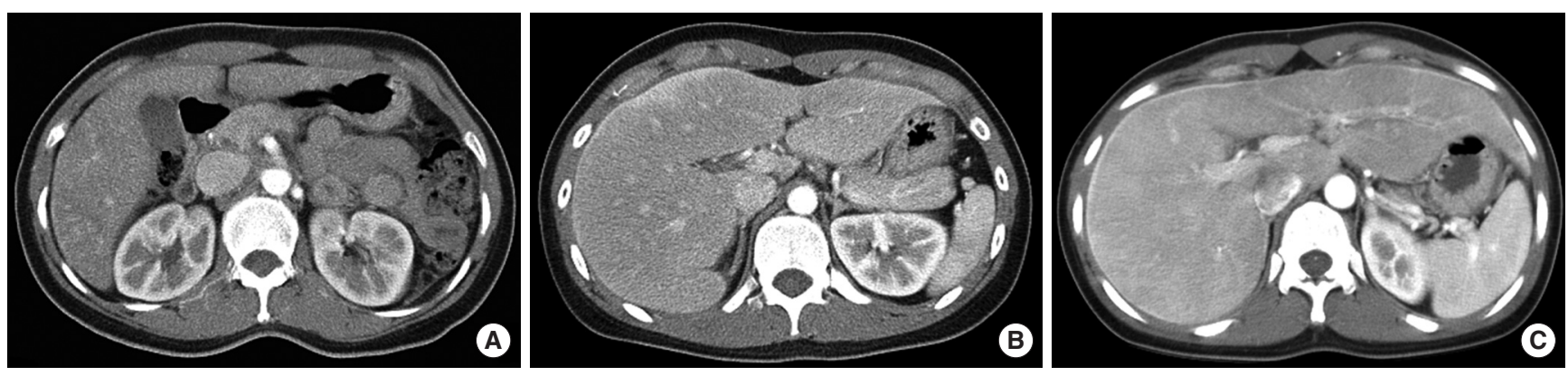

Fig. 1. Images showing the degree of hepatic capsular enhancement in multi-directional computed tomography of patients with Fitz-Hugh-Curtis syndrome. Three different enhancement patterns in Fitz-Hugh-Curtis syndrome are shown in this figure. (A) Weak enhancement pattern: in arterial phase of contrast-enhanced computed tomography, the enhancement of hepatic capsule is identified as partial and weak at the lateral border of the right lobe; (B) moderate enhancement pattern: the enhancement of hepatic capsule is identified as diffuse and weak at the lateral border of the both lobes; and $(\mathrm{C})$ strong enhancement pattern: the enhancement of hepatic capsule is identified as diffuse and strong at the lateral border of both lobes. 
Statistical differences between groups were investigated using $\chi^{2}$ test and Student t-test. Spearman's analysis was used to investigate correlations between variables. Analysis of variance was performed to compare the duration of pain or length of stay between groups. To identify related factors associated with duration of pain or length of stay, linear regression analysis was used. Multivariate models were created using variables that were significant in a univariate analysis $(\mathrm{P}<0.05)$ and clinically relevant. All statistical analyses were performed using R ver. 3.3.3 (The R Foundation for Statistical Computing, Vienna, Austria) and IBM SPSS software ver. 21.0 (IBM Corp., Armonk, NY, USA). Statistical significance was defined at $\mathrm{P}<0.05$.

\section{RESULTS}

\section{Baseline characteristics}

Baseline demographic and clinical characteristics of patients are listed in Table 1. All patients were women of childbearing age. Their mean age was $31.9 \pm 8.8$ years (range, $19-51$ years). The mean duration of pain in patients was about 4.2 days and the total length of stay was about 7 days. All patients recovered within 3 to 14 days. Approximately $85 \%$ of patients were prescribed antibiotics. Ceftriaxone was most common antibiotics, followed by ciprofloxacin. Pericapsular ascites known to indicate severity of the disease was observed in 26 patients (30.2\%).

Although all patients were diagnosed with PID on clinical and imaging studies, positive rates of chlamydia and gonococcus were low. Chlamydia was the most common causative organism. It was found in 10 patients (11.6\%). Patients had a slight increase in white blood cell count (WBC) and an increase in neutrophil fraction. CRP level was at $7.1 \mathrm{mg} / \mathrm{dL}$ on average. It was increased in all patients. However, liver function tests and serum creatinine levels were within normal ranges.

\section{Classification according to the degree of enhancement}

Patients were classified into three groups according to the degree of enhancement of CT findings: weak, moderate, and strong groups (Table 1). As mentioned above, the weak group had a partial weak enhancement (Fig. 1A, pattern A), while the moderate group had a partial strong or diffuse weak enhancement (Fig. 1B,

Table 1. Baseline characteristics according to the degree of hepatic capsular enhancement in computed tomography of patients with Fitz-Hugh-Curtis syndrome

\begin{tabular}{|c|c|c|c|c|c|}
\hline Characteristic & Total (N=86) & Weak (N=28) & Moderate $(\mathrm{N}=35)$ & Strong $(N=23)$ & P-value \\
\hline Age (yr) & $31.9 \pm 8.8$ & $33.8 \pm 7.5$ & $31.9 \pm 10.0$ & $29.5 \pm 8.0$ & 0.072 \\
\hline Female & $86(100.0)$ & $28(100.0)$ & $35(100.0)$ & $23(100.0)$ & \\
\hline Pain duration (day) & $4.2 \pm 1.6$ & $2.9 \pm 0.8$ & $4.3 \pm 1.1$ & $5.7 \pm 1.6$ & $<0.001$ \\
\hline Length of stay (day) & $7.0 \pm 2.6$ & $6.1 \pm 2.4$ & $7.2 \pm 2.9$ & $7.7 \pm 2.2$ & 0.017 \\
\hline Treatment & & & & & 0.213 \\
\hline Ceftriaxone & $52(60.5)$ & $15(53.6)$ & $24(68.6)$ & $13(56.5)$ & \\
\hline Ciprofloxacin & $15(17.4)$ & $4(14.3)$ & $8(22.9)$ & $3(13.0)$ & \\
\hline Other antibiotics & $7(8.1)$ & $2(7.1)$ & $2(5.7)$ & $3(13.0)$ & \\
\hline Conservative treatment & $12(14.0)$ & $7(25.0)$ & $1(2.9)$ & $4(17.4)$ & \\
\hline Pericapsular ascites & $26(30.2)$ & $1(3.6)$ & $10(28.6)$ & $15(65.2)$ & $<0.001$ \\
\hline \multicolumn{6}{|l|}{ Laboratory findings } \\
\hline Chlamydia positivity & $10(11.6)$ & $3(10.7)$ & $4(11.4)$ & $3(13.0)$ & 0.833 \\
\hline Gonococcus positivity & $2(2.3)$ & 0 & $1(2.9)$ & $1(4.3)$ & 0.420 \\
\hline White blood cell $\left(10^{3} / \mu \mathrm{L}\right)$ & $9.4 \pm 3.4$ & $9.9 \pm 4.4$ & $8.9 \pm 2.2$ & $9.5 \pm 3.6$ & 0.911 \\
\hline Absolute neutrophil count $\left(10^{3} / \mu \mathrm{L}\right)$ & $7.0 \pm 3.2$ & $7.4 \pm 4.4$ & $6.5 \pm 1.9$ & $7.1 \pm 3.4$ & 0.870 \\
\hline Hemoglobin (g/dL) & $11.7 \pm 1.4$ & $11.5 \pm 1.6$ & $11.9 \pm 0.9$ & $11.7 \pm 1.7$ & 0.585 \\
\hline Platelet $\left(10^{3} / \mu \mathrm{L}\right)$ & $294.6 \pm 102.6$ & $288.3 \pm 113.3$ & $294.4 \pm 86.5$ & $302.1 \pm 116.0$ & 0.695 \\
\hline C-reactive protein (mg/dL) & $7.1 \pm 6.6$ & $9.6 \pm 7.2$ & $7.0 \pm 6.6$ & $5.4 \pm 5.9$ & 0.057 \\
\hline Aspartate aminotransferase (IU/L) & $22.0 \pm 17.6$ & $20.1 \pm 19.1$ & $22.4 \pm 16.9$ & $23.7 \pm 17.2$ & 0.084 \\
\hline Alanine aminotransferase (IU/L) & $22.8 \pm 31.1$ & $21.7 \pm 39.6$ & $20.8 \pm 25.5$ & $27.1 \pm 28.9$ & 0.158 \\
\hline Total bilirubin (mg/dL) & $0.6 \pm 0.4$ & $0.7 \pm 0.5$ & $0.5 \pm 0.3$ & $0.6 \pm 0.3$ & 0.856 \\
\hline Serum creatinine (mg/dL) & $1.0 \pm 1.3$ & $0.8 \pm 0.1$ & $0.8 \pm 0.1$ & $1.4 \pm 2.5$ & 0.302 \\
\hline
\end{tabular}

Values are presented as mean \pm standard deviation or number $(\%)$. 
Yoo JJ, et al. • Capsular Enhancement Pattern in Fitz-Hugh-Curtis Syndrome
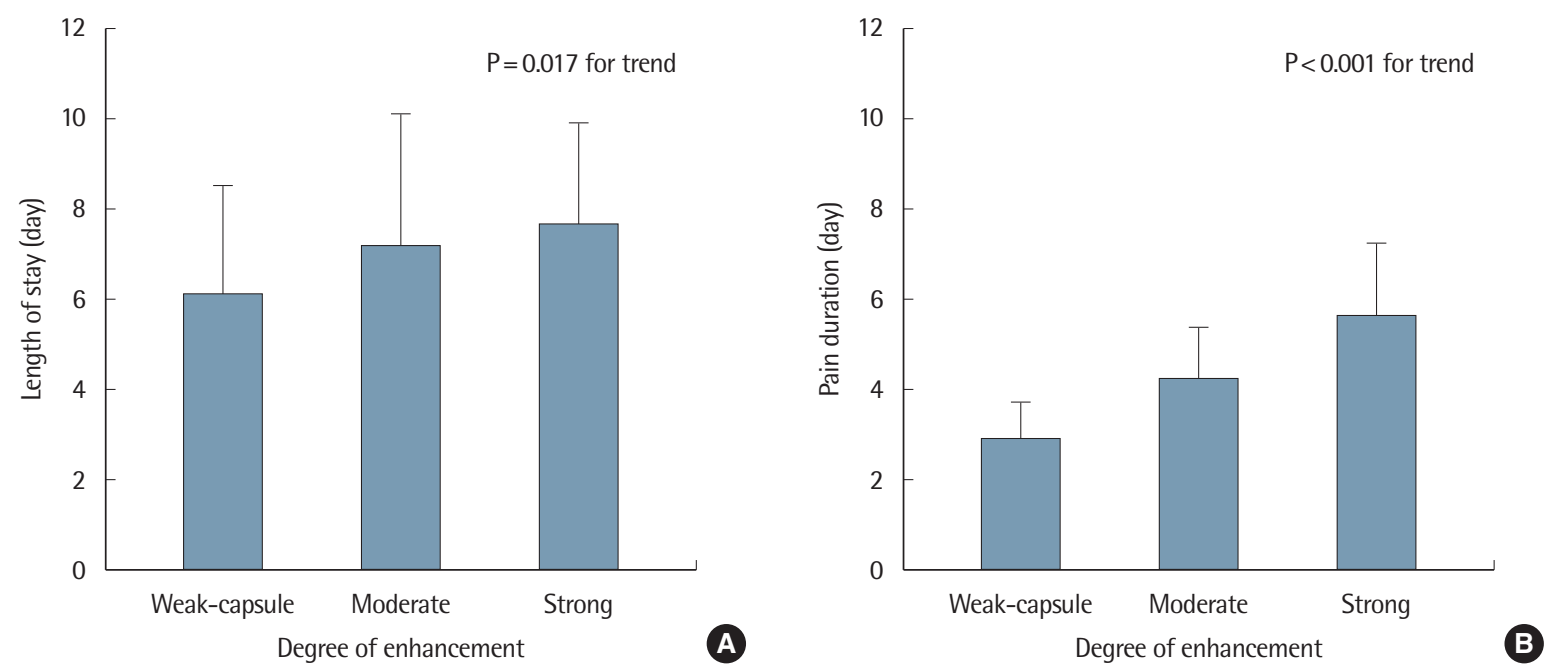

Fig. 2. (A) Length of stay and (B) pain duration according to the degree of enhancement. The degree of perihepatic enhancement showed linear correlation with length of stay $(\mathrm{P}=0.017$ for trend) and pain duration $(\mathrm{P}<0.001$ for trend).

Table 2. Linear regression analysis for length of stay in female patients with Fitz-Hugh-Curtis syndrome

\begin{tabular}{|c|c|c|c|c|}
\hline \multirow{2}{*}{ Variable } & \multicolumn{2}{|c|}{ Univariable } & \multicolumn{2}{|c|}{ Multivariable } \\
\hline & $\mathrm{B}(95 \% \mathrm{Cl})$ & P-value & $\mathrm{B}(95 \% \mathrm{Cl})$ & P-value \\
\hline \multicolumn{5}{|l|}{ Degree of enhancement } \\
\hline Weak & 1 (Reference) & & 1 (Reference) & \\
\hline Moderate & $1.06(-0.24$ to 2.36$)$ & 0.109 & 1.42 (0.34 to1.98) & 0.165 \\
\hline Strong & 1.55 (0.11 to 2.99) & 0.035 & $2.19(0.63$ to 3.76$)$ & 0.007 \\
\hline Age (yr) & $-0.01(-0.07$ to 0.06$)$ & 0.837 & & \\
\hline Chlamydia positivity & $1.71(-0.01$ to 3.43$)$ & 0.052 & & \\
\hline Gonococcus positivity & $3.08(-0.60$ to 6.77$)$ & 0.100 & & \\
\hline Pericapsular ascites & $0.84(-0.37$ to 2.06$)$ & 0.172 & & \\
\hline \multicolumn{5}{|l|}{ Treatment } \\
\hline Conservative method & 1 (Reference) & & & \\
\hline Ceftriaxone & $1.52(-0.14$ to 3.18$)$ & 0.072 & & \\
\hline Ciprofloxacin & $0.98(-1.02$ to 2.99$)$ & 0.333 & & \\
\hline Other antibiotics & $1.82(-0.64$ to 4.29$)$ & 0.146 & & \\
\hline Pain duration (days) & 0.99 (0.70 to 1.28$)$ & $<0.001$ & 1.35 (0.97 to 1.74$)$ & $<0.001$ \\
\hline White blood cell $\left(10^{3} / \mu \mathrm{L}\right)$ & $-0.10(-0.27$ to 0.07$)$ & 0.250 & & \\
\hline Absolute neutrophil count $\left(10^{3} / \mu \mathrm{L}\right)$ & $-0.07(-0.25$ to 0.11$)$ & 0.465 & & \\
\hline Hemoglobin (g/dL) & $-0.04(-0.46$ to 0.38$)$ & 0.839 & & \\
\hline Platelet $\left(10^{3} / \mu \mathrm{L}\right)$ & $0(-0.01$ to 0.01$)$ & 0.936 & & \\
\hline C-reactive protein (mg/dL) & $0.02(-0.10$ to 0.14$)$ & 0.740 & & \\
\hline Aspartate aminotransferase (IU/L) & 0 (-0.03 to 0.03$)$ & 0.974 & & \\
\hline Alanine aminotransferase (IU/L) & $0(-0.02$ to 0.01$)$ & 0.641 & & \\
\hline Total bilirubin (mg/dL) & $0.05(-1.53$ to 1.63$)$ & 0.945 & & \\
\hline Serum creatinine (mg/dL) & $-0.26(-0.69$ to 0.18$)$ & 0.238 & & \\
\hline
\end{tabular}

$\mathrm{Cl}$, confidence interval.

pattern B). Patients in the strong group had a diffuse strong enhancement (Fig. 1C, pattern C). The duration of pain was significantly increased in the order of weak, moderate, and strong groups
( 2.9 vs. 4.3 vs. 5.7 days, $\mathrm{P}<0.001$ for trend). Duration of hospital stay was also increased in the same pattern (6.1 vs. 7.2 vs. 7.7 days, $\mathrm{P}=0.017$ for trend) (Fig. 2). The rate of pericapsular ascites was 
Table 3. Linear regression analysis for pain duration in female patients with Fitz-Hugh-Curtis syndrome

\begin{tabular}{|c|c|c|c|c|}
\hline \multirow{2}{*}{ Variable } & \multicolumn{2}{|c|}{ Univariable } & \multicolumn{2}{|c|}{ Multivariable } \\
\hline & $\mathrm{B}(95 \% \mathrm{Cl})$ & P-value & $\mathrm{B}(95 \% \mathrm{Cl})$ & P-value \\
\hline \multicolumn{5}{|l|}{ Degree of enhancement } \\
\hline Weak & 1 (Reference) & & 1 (Reference) & \\
\hline Moderate & 1.39 (0.80 to 1.97$)$ & $<0.001$ & 1.33 (0.45 to 1.60$)$ & $<0.001$ \\
\hline Strong & 2.77 (2.12 to 3.42$)$ & $<0.001$ & 2.30 (1.79 to 2.81) & $<0.001$ \\
\hline Age (yr) & $-0.02(-0.06$ to 0.02$)$ & 0.272 & & \\
\hline Chlamydia positivity & $0.76(-0.29$ to 1.80$)$ & 0.154 & & \\
\hline Gonococcus positivity & 2.32 (0.13 to 4.51$)$ & 0.038 & & \\
\hline Pericapsular ascites & 1.54 (0.88 to 2.20) & $<0.001$ & 1.54 (0.88 to 2.20) & $<0.001$ \\
\hline \multicolumn{5}{|l|}{ Treatment } \\
\hline Conservative method & 1 (Reference) & & 1 (Reference) & \\
\hline Ceftriaxone & 1.50 (0.54 to 2.46$)$ & 0.003 & 0.96 (0.36 to 1.55$)$ & 0.002 \\
\hline Ciprofloxacin & $1.07(-0.09$ to 2.23$)$ & 0.071 & 0.71 (0 to 1.42$)$ & 0.051 \\
\hline Other antibiotics & 1.71 (0.29 to 3.14$)$ & 0.019 & $0.84(-0.01$ to 1.70$)$ & 0.053 \\
\hline Length of stay (days) & 0.36 (0.25 to 0.46$)$ & $<0.001$ & $1.25(0.98$ to 1.53$)$ & $<0.001$ \\
\hline White blood cell $\left(10^{3} / \mu \mathrm{L}\right)$ & $-0.07(-0.17$ to 0.03$)$ & 0.161 & & \\
\hline Absolute neutrophil count $\left(10^{3} / \mu \mathrm{L}\right)$ & $-0.06(-0.16$ to 0.05$)$ & 0.302 & & \\
\hline Hemoglobin (g/dL) & $-0.04(-0.29$ to 0.21$)$ & 0.742 & & \\
\hline Platelet $\left(10^{3} / \mu \mathrm{L}\right)$ & $0(0$ to 0$)$ & 0.355 & & \\
\hline C-reactive protein (mg/dL) & $-0.03(-0.10$ to 0.04$)$ & 0.338 & & \\
\hline Aspartate aminotransferase e (IU/L) & $0(-0.02$ to 0.02$)$ & 0.647 & & \\
\hline Alanine aminotransferase (IU/L) & $0(-0.02$ to 0.01$)$ & 0.438 & & \\
\hline Total bilirubin (mg/dL) & $-0.32(-1.26$ to 0.62$)$ & 0.497 & & \\
\hline Serum creatinine (mg/dL) & $-0.04(-0.30$ to 0.22$)$ & 0.769 & & \\
\hline
\end{tabular}

$\mathrm{Cl}$, confidence interval.

also significantly increased in the order of weak, moderate, and strong groups (3.6\% vs. $28.6 \%$ vs. $65.2 \%, \mathrm{P}<0.001)$. However, age, selection of antibiotics, causative organisms, WBC, or CRP was not associated with the degree of enhancement.

\section{Related factors determining length of hospital stay}

Next, we examined which factors affected the total length of hospital stay in patients with FHCS through linear regression analyses (Table 2). Univariate analysis showed that the degree of enhancement and pain duration was related to total length of hospital stay. In multivariate analysis, strong enhancement pattern group significantly increased the length of hospital stay (beta coefficient [BE], 2.19; 95\% confidence interval [CI], 0.63-3.76, $\mathrm{P}=0.007)$, even after adjusting for duration of pain.

\section{Related factors determining duration of pain}

Finally, we examined which factors affected the duration of pain in patients with FHCS by linear regression analyses (Table 3). Univariate analysis results showed that degree of enhancement, pres- ence of pericapsular ascites, use of ceftriaxone, and pain duration were related to duration of pain. In multivariate analysis, degree of enhancement was related to pain duration dose-dependently (moderate enhancement: $\mathrm{BE}, 1.33$; $95 \% \mathrm{CI}, 0.45$ to $1.60, \mathrm{P}<0.001$; strong enhancement: $\mathrm{BE}, 2.30$; $95 \% \mathrm{CI}, 1.79$ to $2.81, \mathrm{P}<0.001$ ) after adjusting for other factors. Similar to the previous analysis, hospital stay was closely related to duration of pain in multivariate analysis $(\mathrm{BE}$, 1.25 ; $95 \% \mathrm{CI}, 0.98$ to 1.53 ; $\mathrm{P}<0.001)$. In addition, the use of ceftriaxone significantly reduced pain duration (BE, 0.96; 95\% CI, 0.36 to $1.55 ; \mathrm{P}=0.002$ ).

\section{DISCUSSION}

The prevalence of FHCS is increasing with recent liberalization of sex life compared to the past. Most cases of FHCS can be treated with antibiotics. If not properly treated early, significant morbidity and long-term complication can occur $[19,20]$. Therefore, it is important to determine the severity of FHCS during initial diagnosis. Our results showed that the degree of CT enhancement was 
Yoo JJ, et al. • Capsular Enhancement Pattern in Fitz-Hugh-Curtis Syndrome

closely related to its clinical severity index including hospital admission duration and duration of pain.

Many studies have shown that characteristic imaging finding of FHCS is an ehancement of the liver capsule in arterial phase of CT scan $[2,4,13]$. Previously, many invasive methods such as laparoscopy have been used to diagnose FHCS. However, most of these methods are now replaced by non-invasive methods such as CT $[15,17,18]$. In fact, CT finding and pathological FHCS staging are highly correlated [13]. In addition, CT can help distinguish PID from other diseases that can cause enhancement of liver capsule. However, there is little research on the severity and grading of FHCS. Wang et al. [21] have used liver capsule thickening shape and range on $\mathrm{CT}$ and magnetic resonance imaging examinations for grading FHCS. Kim et al. [18] have proposed a classification system using ehancement site, shape, and thickness changes of liver capsule enhancement using CT scan. However, these classifications are complicated. In addition, they have not been widely applied in clinical practice. The classification method used in this study is advantageous in that it can be applied relatively simply by using ehnacement degree and range only.

We first hypothesized that the degree of ehancement would be directly related to the degree of inflammation. However, the extent of enhancement in CT showed no significant correlation with WBC or CRP level, a biochemical marker of inflammation. This result is consistent with other studies [1]. In previous studies, ESR was elevated in only a few patients while it was within normal range in most patients $[1,22]$. First, FHCS has relatively limited inflammation of peritoneal and perihepatitis. It is possible that the level of systemic inflammation has not increased significantly in these locualted inflammation. For example, in the case of tuboovarian abscess which is the most severe form of PID, the perihepatitis may not be as severe as the sealing effect and may not have a direct correlation with systemic inflammation biomarker [23].

However, CT enhancement grading was closely related to the duration of pain and the entire hospital stay known to be important clinical indicators. In other words, it is impossible to determine the severity of FHCS disease by laboratory finding alone. Image findings are essential for severity determination. Therefore, in patients with strong enhancement of initial CT, it is necessary to administer antibiotics as soon as possible and actively control inflammation and pain by using NSAIDs. This active treatment can result in reduction in overall hospitalization and medical cost. In fact, it has been reported that the faster the appropriate antibi- otic is administered, the faster the symptom control and the lower chance of complication [24].

Neisseria and Chlamydia are the two most common etiological organism causing FHCS. However, the difference in enhancement pattern was not significant accroding to etiological organism in this study. The causative organism of FHCS is mainly dependent on past research. In the past, the ratio of Neisseria and Chlamydia reached 90\% [25,26]. However, it seems that FHCS is caused more by organisms other than Neisseria and Chlamydia recently due to liberalization of sexual life and diversification of STD [25,27,28].

In our study, pain duration was significantly shorter when ceftriaxone was used. In the case of STD, coexisting cases are frequent. If suspected bacteria are not clearly identified, it is a principle to treat the possible bacteria simultaneously [29]. The results of this study suggest that ceftriaxone has a wider coverage than other antibiotics (tetracycline, macrolide, etc.). Thus, it may improve PID symptoms more effectively.

In conclusion, the CT enhancement pattern in FHCS is closely related to its clinical severity and the course of this disease. $\mathrm{Pa}$ tients with strong enhancement pattern may require faster treatment and active pain control. Additional research is needed to determine the relationship between the enhancement pattern and pathogens or choice of appropriate antibiotics in the future.

\section{REFERENCES}

1. Khine H, Wren SB, Rotenberg O, Goldman DL. Fitz-Hugh-Curtis syndrome in adolescent females: a diagnostic dilemma. Pediatr Emerg Care 2019;35:e121-3.

2. Sonavane AD, Rathi PM. Fitz-Hugh-Curtis syndrome. Indian J Med Res 2017;145:147.

3. Basit H, Pop A, Malik A, Sharma, S. Fitz Hugh Curtis syndrome. Treasure Island (FL): StatPearls Publishing; 2019.

4. Jia W, Fadhlillah F. Fitz-Hugh-Curtis syndrome: a diagnostic challenge. Clin Case Rep 2018;6:1396-7.

5. Guo TJ, Yang Y, Chen DF, Guo Y. 2 Cases of Fitz-Hugh-Curtis syndrome. Zhonghua Gan Zang Bing Za Zhi 2018;26:469-70.

6. Gatt D, Jantet G. Perisplenitis and perinephritis in the Curtis-Fitz-Hugh syndrome. Br J Surg 1987;74:110-2.

7. Peter NG, Clark LR, Jaeger JR. Fitz-Hugh-Curtis syndrome: a diagnosis to consider in women with right upper quadrant pain. Cleve Clin J Med 2004;71:233-9.

8. Vieira JT. Acute gonococcic peritonitis in the right upper quadrant in women; Fitzhugh syndrome. Rev Bras Med 1950;7:287-9.

9. Muller-Schoop JW, Wang SP, Munzinger J, Schlapfer HU, Knoblauch M, Tammann RW. Chlamydia trachomatis as possible cause of peritonitis and perihepatitis in young women. Br Med J 1978;1:1022-4.

10. Amman R, Zehender O, Jenny S, Bass G. Acute gonococcal perihepatitis (Fitz-Hugh-Curtis syndrome): an acute, right-side "pleuritic-peritonitic" 
upper abdominal pain syndrome in Adnexitis gonorrhoica: diagnosis by laparoscopy. Dtsch Med Wochenschr 1971;96:1515-9.

11. Stanley MM. Gonococcic peritonitis of the upper part of abdomen in young women; (phrenic reaction, or subcostal syndrome of Stajano; FitzHugh-Curtis syndrome); report of cases of three patients treated successfully with penicillin and a summary of the literature. Arch Intern Med (Chic) 1946;78:1-13.

12. Simon EM, April MD. Fitz-Hugh-Curtis syndrome. J Emerg Med 2016; 50:e197-8

13. Wang PY, Zhang L, Wang X, Liu XJ, Chen L, Wang X, et al. Fitz-HughCurtis syndrome: clinical diagnostic value of dynamic enhanced MSCT. J Phys Ther Sci 2015;27:1641-4.

14. Yang HW, Jung SH, Han HY, Kim A, Lee YJ, Cha SW, et al. Clinical feature of Fitz-Hugh-Curtis syndrome: analysis of 25 cases. Korean J Hepatol 2008;14:178-84.

15. Le Moigne F, Lamboley JL, Vitry T, Salamand P, Milou F, Farthouat P. Usefulness of contrast-enhanced CT scan for diagnosis of Fitz-Hugh-Curtis syndrome. Gastroenterol Clin Biol 2009;33:1176-8.

16. Demelo-Rodriguez P, Gonzalez-Munera A, Tejerina F, Bernaldo De Quiros JC. Fitz-Hugh-Curtis syndrome in subacute/acute phase. Rev Clin Esp 2013;213:e49.

17. Joo SH, Kim MJ, Lim JS, Kim JH, Kim KW. CT diagnosis of Fitz-Hugh and Curtis syndrome: value of the arterial phase scan. Korean J Radiol 2007;8:40-7.

18. Kim JY, Kim Y, Jeong WK, Song SY, Cho OK. Perihepatitis with pelvic inflammatory disease (PID) on MDCT: characteristic findings and relevance to PID. Abdom Imaging 2009;34:737-42.
19. Zeger W, Holt K. Gynecologic infections. Emerg Med Clin North Am 2003;21:631-48.

20. Hong DG, Choi MH, Chong GO, Yi JH, Seong WJ, Lee YS, et al. FitzHugh-Curtis syndrome: single centre experiences. J Obstet Gynaecol 2010;30:277-80.

21. Wang CL, Guo XJ, Yuan ZD, Shi Q, Hu XH, Fang L. Radiologic diagnosis of Fitz-Hugh-Curtis syndrome. Chin Med J (Engl) 2009;122:741-4.

22. Park ST, Lee SW, Kim MJ, Kang YM, Moon HM, Rhim CC. Clinical characteristics of genital chlamydia infection in pelvic inflammatory disease. BMC Womens Health 2017;17:5.

23. Bellini PG, Gargano N, Giannone S. Influence of the relative environmental humidity on some respiratory function tests in subjects with pulmonary silicosis. Boll Soc Ital Biol Sper 1970;46:676-9.

24. Cho HJ, Kim HK, Suh JH, Lee GJ, Shim JC, Kim YH. Fitz-Hugh-Curtis syndrome: CT findings of three cases. Emerg Radiol 2008;15:43-6.

25. Darougar S, Forsey T, Wood JJ, Bolton JP, Allan A. Chlamydia and the Curtis-Fitz-Hugh syndrome. Br J Vener Dis 1981;57:391-4.

26. You JS, Kim MJ, Chung HS, Chung YE, Park I, Chung SP, et al. Clinical features of Fitz-Hugh-Curtis syndrome in the emergency department. Yonsei Med J 2012;53:753-8.

27. Keane JA, McKimm RJ, David CM. Perihepatitis associated with pelvic infection: the Fitz-Hugh-Curtis syndrome. N Z Med J 1982;95:725-8.

28. Fransen L, Avonts D, Piot P. Genital chlamydial infection associated with perihepatitis (Fitz-Hugh-Curtis syndrome). Acta Clin Belg 1982;37:314-7.

29. Verlee EL, van Bergen JE, Dekker JH, Boeke AJ, Burgers JS, Bouma M. Summary of the NHG guideline 'the STD consultation'. Ned Tijdschr Geneeskd 2014;158:A7277. 